\title{
Using the Malmquist Index in Evaluation Process to Enhance Mathematical Literacy in High School Students
}

\author{
Niusha Mostoli (id) ${ }^{1}$, Mohsen Rostamy (id) 1,*, Ahmad Shahverani ${ }^{\mathbf{1}}$, \\ Mohammad Hasan Behzadi 1
}

${ }^{1}$ Department of Mathematics, Science and Research Branch, Islamic Azad University, Tehran, Iran

\author{
ARTICLE HISTORY \\ Received: 21 September 2019 \\ Revised: 22 November 2019 \\ Accepted: 17 December 2019 \\ KEYWORDS \\ Productivity Evaluation, \\ The Malmquist Index, \\ Mathematical Literacy, \\ Evaluation instrument \\ GAMS,
}

\begin{abstract}
The study aimed to calculate the evaluation of $9^{\text {th }}$ grade female students and compare the development of the educational process in increasing mathematical literacy using the Malmquist Index at different time intervals. This educational process was accomplished by analysing and integrating realistic mathematical education and mathematical problem-solving. The populations of the study were 120 ninth grade female students. Each student was as a DMU whose inputs were the math test score and the outputs were math test score of December and June. The data analysis method was based on (DEA) technique to calculate efficiency. The output-driven (CCR) model was used to determine students' performance coefficient. Then, the Malmquist Index was used to compare productivity evaluation after the end of the training course in December and the end of the year in June. In general, the results from changes in productivity evaluation of students using the Malmquist Index showed that the students in the experimental group who learned problem-solving and realistic mathematics had an increase in the overall productivity evaluation factor after completing the training compared to the others.
\end{abstract}

\section{INTRODUCTION}

We live in a developing world where if we do not nurture students with an efficient and dynamic education system, we will be left out of world educational standards. That's why education has long been of particular interest to mankind. Today, in modern societies, statesmen believe that an integrated curriculum must be used to advance and achieve the prescribed goals. One of the biggest challenges in writing an integrated curriculum at any level is to make the complex concepts understandable at the same time with preserving their integrity for students (Fendel, 2012). Learning math is different from learning other subjects for different reasons. Mathematics is the language of nature's explanation and is based on reason and creativity. Besides examining the targeted learning content, the use of modern methods in evaluating the educational methods is another concern of the educational system of any country. Education system plays an essential role in economic and social development of any country because of its mission in raising the required expert manpower. Therefore, assessing the performance of its different domains is of great importance (Stacey et al., 2015). In addition to satisfying

CONTACT: Mohsen Rostamy $₫$ Mohsen_rostamy@yahoo.com $\equiv$ Department of Mathematics, Science and Research Branch, Islamic Azad University, Tehran, Iran 
personal interests, mathematics has also been studied for practical objectives in other fields of study (Gatabi, Stacey, \& Gooya, 2012). In confirming the effective communication of mathematics with other scientific fields, Gauss considered the math as the queen of sciences (Gatabi et al., 2012).

A closer look can show the effect of math skills on different levels of life. Hence, it can be said that student math success is always dependent on the future of a country, so the desire to understand and identify the factors leading to student math success, it has always been crucial to national leaders, policymakers, and educators (Burnett, 2005). According to Freudenthal, math must be taught for its usefulness, and of course this is not achieved through useful mathematical teaching, since any subject of mathematics can, however, be useful in limited fields (Gravemeijer \& Terwel, 2000). One of these useful methods is problem-solving and combining it with the real world. Problem-solving is a vital skill for living in the present age. Nowadays, authorities are called for high-level thinking skills and problem-solving, both in the public and in the field of technologies in all activities (Stacey et al., 2015).

Given the importance of mathematics training and the stated goals, it is clear that the real-world problem-solving ability is one of the issues emphasized and endorsed by policy makers in the education system. One way to determine the realization of these goals are identification and participation in international tests. Programme for International Student Assessment (PISA) is an international study that emphasizes the application of mathematics to everyday life. The main question of the PISA study of Organization for Economic Cooperation and Development on mathematics is if students are mathematically prepared for future challenges (Adams \& $\mathrm{Wu}$, 2000). The PISA study has emerged to answer the assessment of 15 -year-old students' readiness to address future challenges in after-school life, not just school life. This study has been conducted every three years since 2000 (OECD, 2002). The tests used in PISA studies include issues that measure students' ability to cope with real-world challenges, taking into account different criteria (Development, n.d.)

\subsection{In framework of the PISA study, mathematical literacy is defined as follows:}

Mathematical literacy is an individual's talent to formulate, apply, and interpret mathematics in a variety of fields, including mathematical reasoning and the use of mathematical concepts, methods, facts, and tools to describe, express, and predict phenomena. Mathematics literacy helps people to understand the role of mathematics in the world and to make the reasonable judgments and decisions needed for a productive, committed and thoughtful citizen (Alvarez, 2018).

Real-world applications of the curriculum are serious challenges in targeting the school curriculum. Given recent targeting in education organization, it is important to address students' ability to apply mathematics in everyday life. A topic of interest today is the gap between the mathematical world and the real world, resulting in students' inability to use mathematics in the real world (Alimohammadlou \& Mohammadi, 2016). According to the latest National Curriculum Document, students' empowerment in applying mathematics to solve everyday problems and abstractions are one of the main goals of mathematical education in the education system (Gravemeijer, 1994). In addition, the Higher Education Council in the first high school goals approval emphasizes that first-grade high school students must be proficient in the use of mathematics to solve problems for themselves and society at the end of the course. Mathematics education should therefore provide an opportunity for students to experience the relationship between the real world and the mathematical world, thereby solving their everyday problems (Breen, Cleary, \& Shea, n.d.).

It can now be argued that the education system undoubtedly needs performance evaluation and assessment in order to make the best use of its limited resources and better effectiveness. One 
of the most effective tools in this field is data envelopment analysis which is used as a nonparametric method to calculate the efficiency of decision making units (Charnes, Cooper, \& Rhodes, 1978). Today, DEA technique is rapidly expanding and is being used in the evaluation of various organizations and industries such as the banking industry, post offices, and hospitals, training canters, power plants, refineries and more (Wang \& Lan, 2011). Various papers and studies have been presented to date based on this technique, which are mainly based on conventional DEA models, such as CCR, BCC, etc. These models are not capable of evaluating the performance of multiple-component decision making units (Färe, Grosskopf, \& Roos, 1995). Management needs methods to do so because of the need to know the performance of system components. Therefore, in 1989, scientists such as Fare, Grosskopf, Lindgren and Roos used the data envelopment analysis technique to calculate the Malmquist Index. In 1992, the Malmquist Index was divided into two factors, efficiency changes, technology changes, and changes in technology by the scientists. Every effort to increase efficiency and productivity, which involves measuring, analysing, planning and improving productivity, falls into the productivity cycle, and measuring productivity evaluation is the first and foremost task in this cycle (Fare, Grosskopf, Lindgren \& Roos, 1992).

\subsection{In this regard, the present study seeks to answer the following questions:}

- Does a teaching problem-solving technique help students to change, apply and interpret the relationship of content areas to problems and find solutions?

- Does a teaching realistic math technique help students apply math textbook problems and model simple real-life situations?

- Are the Malmquist and the GAMS effective tools in evaluating the performance of $9^{\text {th }}$ grade students in mathematics literacy test?

- Is it possible to evaluate and compare students' performance using the Malmquist Index and Data Envelopment Analysis?

\subsection{Conceptual definitions}

Data Envelopment Analysis: It is a mathematical programming-based method that enables the calculation of technical performance and Evaluate the data for desired programs with some inputs and outputs of decision making units (DMU) without assigning weights to inputs and outputs and matching them (Sağlam, 2017).

The output-driven CCR model: The name of this model (CCR) is derived from the first letters of the three scholars, namely, Charles, Cooper, and Rhodes. The model has constant-scale output. The output models seek to maximize outputs without any increase (change or decrease) in the amount of inputs(Sinuany-Stern, Mehrez, \& Barboy, 1994). The purpose of this mode is to maximize the output without increasing inputs or resources. The model is shown in equation 1:

$$
\begin{aligned}
& \operatorname{Max} \varphi \\
& \sum_{j=1}^{\text {s.t }} \gamma_{j} x_{i j} \leq x_{i o}, \quad i=1, \ldots, \\
& \sum_{j=1}^{n} \gamma_{j} y_{r j} \geq \varphi y_{r o}, \quad r=1, \ldots, s \\
& \gamma_{j} \geq 0, \quad j=1, \ldots, n
\end{aligned}
$$


The model is always feasible and the optimal solution applies to the condition $\varphi^{\wedge * \geq 1}$. If $\varphi^{\wedge *}=1$ then the DMU is technically efficient in the nature of the output. If $\varphi^{\wedge *>}>1$ then the DMU is inefficient in the nature of the output (Basic \& Model, 2005). Using this data envelopment analysis model to calculate the efficiency and rankings of units, more than one unit may achieve the highest efficiency coefficient, i.e. 1 . In this case, it is not possible to compare and rank these efficient units. In this case, the Anderson-Peterson (AP) method can be used to rank efficient units (Charnes et al., 1978).

Anderson and Petersen Ranking (AP): Anderson and Petersen (1993) have developed a method that is suitable for ranking efficient units and can help to compare and contrast units that have performance 1 . The method in linear programming model for DMU with efficiency 1 , smaller constraint and equal to zero; corresponding to DMU is eliminated so that DMU does not face resource constraint (Hosseinzadeh Lotfi et al., 2013). Then the model is resolved after the changes are made. In this case the efficiency coefficient of the efficient units may be larger, the unit is more efficient (Andersen \& Petersen, 1993).

Productivity: The performance of a company in converting the input to the output can be expressed in a variety of ways. One of the ways to measure performance is productivity ratio. By defining a firm's productivity as the output-to-input ratios, values larger than this ratio reflect the firm's better performance. The profitability is a relative relationship. Productivity is the efficiency in using measured resources as the output relative to input. To calculate productivity, it is necessary to calculate the input and output values. Productivity is technically broken down into two factors: efficiency and effectiveness (Tohidi \& Razavyan, 2013).

Efficiency: It is the ratio of actual yields to standardized and expected yields of efficiency, or in fact the ratio of the amount of work done to the amount of work to be done (Emrouznejad \& Yang, 2018).

Malmquist: The Malmquist Productivity Evaluation Index is a two-way Index that calculates productivity growth between two units (firm) in one period, or one firm in two different periods. Stan Malmquist, Swedish economist, (1953) introduced the Malmquist Index as the standard of living, and in 1982, it was first applied to production theory by Christensen and Diewert (Caves, Christensen \& Diewert, 2012). In 1989, Farr et al., used data envelopment analysis to calculate the Malmquist Index, and in 1994, the Index was broken down into two factors: efficiency and technology (Balf, Lotfi, \& Alizadeh, 2010). The data computed for the distance functions are the technical efficiency obtained from data envelopment analysis equations. Thus, the Malmquist Productivity Index is defined by the maximization between the two times $t$ and $t+$ 1 , with respect to the common efficiency boundary at time $t$ as equation 2 .

$$
M_{0}^{t}\left(Y_{t}, X_{t}, Y_{t+1}, X_{t+1}\right)=\frac{d_{0}^{t}\left(Y_{t+1}, X_{t+1}\right)}{d_{0}^{t}\left(Y_{t}, X_{t}\right)}
$$

Similarly, the Malmquist Productivity Index is defined by the maximization between the two times $t$ and $t+1$ with respect to the current efficiency boundary at time $t+1$ as the equation 3 .

$$
M_{0}^{t+1}\left(Y_{t}, X_{t}, Y_{t+1}, X_{t+1}\right)=\frac{d_{0}^{t+1}\left(Y_{t+1}, X_{t+1}\right)}{d_{0}^{t+1}\left(Y_{t}, X_{t}\right)}
$$

The two Malmquist indices are equivalents, and the Malmquist productivity change Index is expressed as the geometric mean of the two productivity indices and can be represented by the equation 4.

$$
M_{0}\left(Y_{t}, X_{t}, Y_{t+1}, X_{t+1}\right)=\left[\frac{d_{0}^{t+1}\left(Y_{t+1}, X_{t+1}\right)}{d_{0}^{t+1}\left(Y_{t}, X_{t}\right)} \times \frac{d_{0}^{t}\left(Y_{t+1}, X_{t+1}\right)}{d_{0}^{t}\left(Y_{t}, X_{t}\right)}\right]^{\frac{1}{2}}
$$

This productivity equation expresses the point $\left(\mathrm{Y}_{(\mathrm{t}+1)}, \mathrm{X}_{(\mathrm{t}+1)}\right)$ versus point $\left(\mathrm{Y}_{t}, \mathrm{X}_{\mathrm{t}}\right)$. Values 
greater than one represent productivity growth. If performance declines during the trend, the Malmquist Index will be less than 1. Equation 4 can be broken down into equation 5 to allow the Malmquist Index to show technological change, production scale and technical efficiency (Wang \& Lan, 2011).

$$
M_{0}\left(Y_{t}, X_{t}, Y_{t+1}, X_{t+1}\right)=\frac{d_{0}^{t+1}\left(Y_{t+1}, X_{t+1}\right)}{d_{0}^{t}\left(Y_{t}, X_{t}\right)}\left[\frac{d_{0}^{t}\left(Y_{t+1}, X_{t+1}\right)}{d_{0}^{t+1}\left(Y_{t+1}, X_{t+1}\right)} \times \frac{d_{0}^{t}\left(Y_{t}, X_{t}\right)}{d_{0}^{t+1}\left(Y_{t}, X_{t}\right)}\right]^{\frac{1}{2}}
$$

In equation 5 , the term outside the bracket represents the change in the technical efficiency at $t$ and $t+1$ and equals to the ratio of the technical efficiency at time $t+1$ to the technical efficiency at time $t$. The term inside the bracket represents the technological shift between the two above times. $M_{0}$ greater than 1 indicates that productivity evaluation has increased between the two periods. This increase can be based on technical efficiency or technology advancement (change of efficient border) (Diewert \& Fox, 2010).

Realistic Mathematical Education: In the late 70s, Freudenthal et al., objected to the American movement and the mechanical mathematics education approach in the Netherlands, and explained the theory of realistic mathematics education (the new mathematics) to reform the process of teaching and learning mathematics (Lange, 1987). The underlying philosophy of realistic mathematic education was that the learner needed to gain mathematical understanding by working on the fields which was meaningful for him (Freudenthal, 1973). In his view, the real world is the source or starting pint of mathematic concept development (Koyuncu, Guzeller, \& Akyuz, 2016). Mathematics education in this way is guided by reinvention so that the student can experience it himself (Esther, Pérez, Duque, \& García, 2018). The three key principles of this approach are Guided reinvention, didactical phenomenology, and self-developed model (Sumirattana, Makanong, \& Thipkong, 2017).

Problem-Solving: From George Polya's perspective, problem-solving strategy is done in the following four steps (Pólya, 1962):

1. (Understanding the problem) what is required in the problem?

2. (Deeper recognition of problem and map design) how the different components of the problem are interconnected and what is the missing link to the problem data?

3. (Implementation of map for problem-solving) this step depends on the correct implementation of steps 1 and 2. In fact, the major task to solve the problem is to get an idea of what the map is and how it works.

4. (Review and getting back) controlling the correct execution of the map (Esther et al., 2018).

The problem-solving process in this research is based on the Polya's mathematical model and the Shewhart cycle consisting of five parts that including Definition D, Assessment A, plan P, Implementation I, communication C, (Sumirattana et al., 2017).

The PISA Study: The first PISA study was conducted in 2000. The study was held every three years and the results of each course were published by the Organization for Economic Cooperation and Development. The main question of the PISA about mathematics is whether 15-year-old students are mathematically prepared for future challenges in after-school life. Testing this study focuses on real-world mathematics and operates beyond the school matters(Programme for International Student Assessment \& OECD 2009).

Evaluation Instrument GAMS: software is a powerful and comprehensive tool for solving mathematical models even in large dimensions and disciplines of science, that is, wherever it is necessary to make optimal decisions with time, cost, and resources, the mathematical modelling should be used and GAMS is a highly efficient tool for solving these types of models. The most important application of GAMS is the optimization of research models in operations and data envelopment analysis and data evaluate (Rosenthal, 2007). 


\subsection{Research history}

One of the researches related to mathematical literacy assessment in the world is a research in which a test is designed to fit the mathematical knowledge level of 15 years old students. Based on the results of this study, the mathematical literacy of these students is reported in the field of understanding undesirable problem and in the field of interpreting, using processes, modelling and very undesirable describing (Sari \& Valentino, 2016).

In another study in Turkey, students' success rates in answering a variety of the PISA test questions in 2003 and 2012 were compared. According to this study, students have been more successful in the both years in answering multiple-choice questions (Thomson, Hillman, \& Bortoli, 2013).

In another study, students' performance in dealing with new problems but commensurate with their mathematical knowledge was measured by a PISA test. The results of this study suggest that math literacy among Irish 18- and 19-year-old students has been at a desirable level due to their education in engineering fields, which is expected because of mathematical training (Breen, Cleary, \& Shea, n.d.)

Koçak, Türe and Atan (2019) in another study did researches Efficiency Measurement with Network DEA. They did compute the educational economy efficiency of the Organisation for Economic Co-operation and Development. They study is the use of a novel approach to computing the educational economic efficiency using relational network DEAL with GAMS (Koçak et al, 2019).

Chen and Yao (2010) calculated the Malmquist Index for measuring total productivity changes and its components in three important industries of China, including textile, chemical and metal industries during four development plans of China by using Data Envelopment Analysis Method. The results showed that productivity changes in 1966 in the fourth and fifth programs compared to the previous programs, but in the sixth plan slightly increased (about 3 to 5\%). Total productivity components didn't change significantly during programs (Chen \& Lin, n.d.).

Wei and Hao (2011) studied the role of human capital on the total productivity growth of factors in 30 Chinese provinces during 1985-2004 and used the Malmquist Index to measure productivity growth. Results indicated that human capital had a positive significant effect on the total productivity growth (Wei \& Hao, n.d.).

Maodus et al., (1998) examined the effect of human capital on productivity in OECD countries during 1965-1990. They used data envelopment analysis to perform this study. Results showed that higher level of human capital increases productivity (Maudos \& Pastor, 1998).

Chen and Lin (2006) conducted a case study on the R\&D performance of 52 integrated semiconductor companies located at the Sino Chou Science and Technology Park in Taiwan using the DEA approach. Using the BCC model, they calculated the rates of technical and scale efficiency. Results showed that R\&D performance is very different among the firms evaluated, and many inefficient firms have to increase their economic scales (Chen \& Lin, n.d.).

\section{METHOD}

\subsection{Variables}

Accurate and appropriate selection of inputs and outputs is one of the determinants of achieving reliable and proportional outcomes for educational purposes in order to calculate correct values of productivity in different periods. In this study, each student is considered as a DMU with two approaches to realistic mathematics education and the problem-solving process. Input of each DMU (student) includes two realistic math instruction and math problem-solving methods. The outputs in each DMU includes performance of each student using a mathematical literacy 
performance assessment taking into account the score obtained in pre-test in the beginning of the academic year $\mathrm{M}$ and the mathematical post-test will be at the end of the first three months $\mathrm{A}$ and the final exam at the end of academic year P. Finally, the productivity was calculated using the Malmquist Index in the A-M and A-P intervals. GAMS software was used to calculate the efficiency and productivity evaluation and finally the efficient units were sorted by the Anderson and Peterson AP ranking method.

\subsection{Methods}

The statistical population consisted of the $9^{\text {th }}$ grade female students of District 3 of Tehran. The sample was selected by simple random sampling due to the high size of the statistical population. 120 students were selected as the experimental group, dividing into 4 classes based on Table 1 .

Table 1. Classes Model

\begin{tabular}{lll}
\hline Trained education methods & Number & Class \\
\hline Just problem-solving (PS) & 30 & $\mathrm{~A}$ \\
\hline Just realistic mathematical method (RME) & 30 & $\mathrm{~B}$ \\
\hline Both educational methods (PS \& RME) & 30 & $\mathrm{C}$ \\
\hline Without educational method & 30 & $\mathrm{D}$ \\
\hline
\end{tabular}

Before performing the research, students were given a mathematical pre-test that questions were calculated similar to post-test with validity and reliability $(r=0.209-0.743, p=0.243-0.569)$ and Cronbach's alpha 0.754 The math pre-test was conducted at the beginning of the $\mathrm{M}$ academic year. After doing the research to evaluate the students' mathematical literacy and calculating the final efficiency of questions, math post-test was conducted based on the PISA (2015) at the end of our first three academic years A. The questions in this test were consistent with realistic mathematics content and in accordance with the objectives of mathematical problem-solving. First, students were given mathematical literacy pre-test, and then students of experimental group were taught problem-solving and realistic mathematics in 12 weeks. Finally, the mathematics test at the end of academic year P was conducted in June. After localization, the final test was given to the experts to criticize the publishable questions in the PISA Studies 2012. After making corrections and approving by the experts, taking into account the mathematical knowledge of 15-year-old students, a number of questions that did not fit with the topics of mathematics books being taught in Iran were eliminated. Finally, a test consisting of 10 questions with maximum similarity to the mathematical test of PISA was prepared. The questions were given to several mathematics professors and mathematics educators and some experienced high school math teachers and approved after review. Based on primary study, Cronbach's alpha coefficient of this test was 0.73 . Given that this value was greater than 0.7 , it showed good reliability. As mentioned earlier, students were taught problem-solving and realistic mathematics methods in 12 weeks:

First three weeks of the course: Students were taught that the following should be clear to solve a problem: What to find? What is the unknown? What is the assumption? What is the known? What is the relationship between known and unknown? Students review the content of the problem; the teacher should guide them based on their request and teach them how to use and apply mathematical definitions. Students need to evaluate problem situations to provide meaningful, simple models for problem-solving.

Second three weeks of the course: Students were taught to draw a problem-solving map using tables, figures, diagrams, and data, so they could figure out a correct way to solve it.

Third three weeks of the course: The students were taught to apply all their guesses and plans until they felt that they might not solve the problem, so they could prepare and execute a new 
project.

Final three weeks of the course: The student was finally taught to review all the steps taken, re-examine their arguments and answers, and analyse the correctness of their solution.

Notice that throughout the courses, inspired by realistic mathematics, students were given the opportunity to create their own mathematical knowledge, invent new mathematics, and relate abstract mathematics to the real world. Given that each student is considered as a DMU, the performance of each student in the first stage was calculated with the first test score in October and the second test score in December EMA and in the second stage with the second test score in December and score the final test in June EAP. The total score of each test is 20, i.e. 10 questions with 2 points each. The performance of the data was calculated using the output-driven CCR model. At the end of the year after the calculation of final performance, the Malmquist Index was used to calculate data productivity evaluation. The research model is presented in Figure 1.

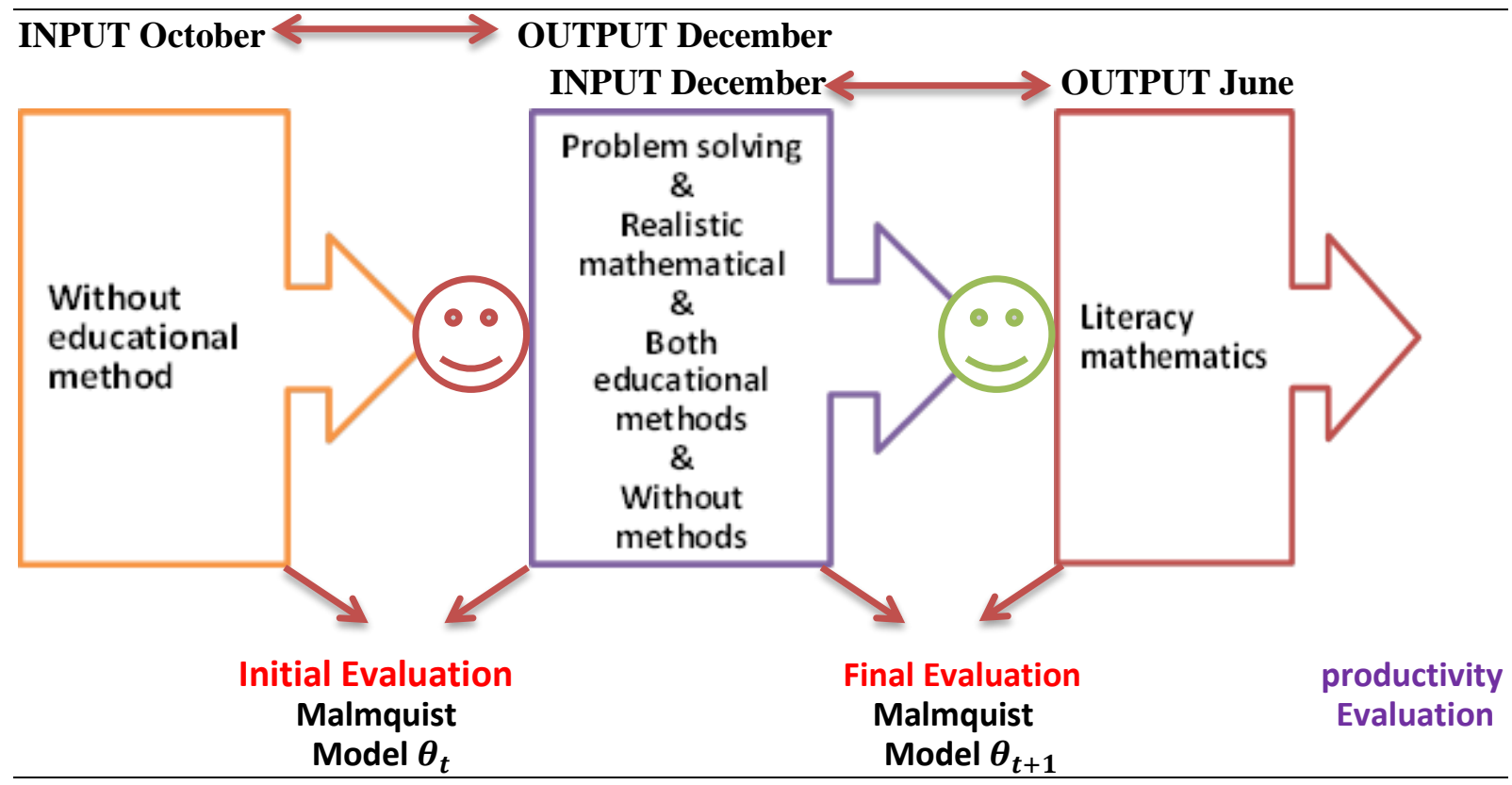

Figure 1. Input \& Output Model of the Malmquist Index

\section{RESULT}

In this section, considering the results of tests taken by the students, data will be described and the questions answered. Table 2 briefly refers to the used terms.

Table 2. Abbreviation Table

\begin{tabular}{llll}
\hline Abbreviation & Explanation & Abbreviation & Explanation \\
\hline DMU & Decision Making Unit & TCI & Technical Change Index \\
\hline RME & Realistic Mathematics Education & SECI & Scale Efficiency Change Index \\
\hline PS & Problem Solving & FGLR & Fare, Grosskof, Lindgren and Roos \\
\hline EMA & Efficiency October-December & FGLR & Malmquist Model \\
\hline EAP & Efficiency December- June & FPCI & Factory Productivity Change Index \\
\hline
\end{tabular}


Question 1: Does teaching problem-solving techniques and applying and interpreting change the content contexts of problems and finding solutions, help students?

Inputs are Class A who received math problem-solving training and the output is enhanced math literacy according to Table 3. The mean percent of performance in the initial test before problem-solving method was $23.3 \%$ and at the end of training $36.6 \%$ and the mean productivity with the Malmquist Index was $63.3 \%$. At a glance, according to Table 3, it can be said that students' mathematical performance after receiving problem-solving, had better results for Class A. Although the number of students who became effective after receiving the problemsolving instruction was not high, the math scores with the Malmquist mean score showed improvement in the final math test.

Table 3. Problem-Solving Efficiency

\begin{tabular}{|c|c|c|c|c|c|c|c|}
\hline CLASS A & & & & & & & \\
\hline ROW & DMU & E(MA) & $\mathbf{E}(\mathbf{A P})$ & TCI & SECI & FGLR & FPCI \\
\hline 1 & DMU1 & 0.807 & 1.002 & 0.998 & 1.232 & 1.229 & Increase \\
\hline 2 & DMU2 & 1 & 0.875 & 0.947 & 0.875 & 0.829 & Decrease \\
\hline 3 & DMU3 & 0.969 & 0.797 & 1.193 & 0.823 & 0.982 & Decrease \\
\hline 4 & DMU4 & 0.81 & 0.719 & 0.984 & 0.888 & 0.874 & Decrease \\
\hline 5 & DMU5 & 1 & 1 & 0.074 & 1 & 0.974 & Decrease \\
\hline 6 & DMU6 & 0.722 & 0.733 & 0.975 & 1.044 & 1.018 & Increase \\
\hline 7 & DMU7 & 0.954 & 0.906 & 0.907 & 0.905 & 0.922 & Decrease \\
\hline 8 & DMU8 & 1 & 1 & 0.939 & 1 & 0.939 & Decrease \\
\hline 9 & DMU9 & 0.715 & 0.784 & 0.98 & 1.098 & 1.076 & Increase \\
\hline 10 & DMU10 & 0.392 & 1 & 0.971 & 1.038 & 1.007 & Increase \\
\hline 11 & DMU11 & 1 & 1 & 1.640 & 1 & 1.640 & Increase \\
\hline 12 & DMU12 & 0.665 & 1.01 & 1.201 & 1.177 & 1.413 & Increase \\
\hline 13 & DMU13 & 0.734 & 0.704 & 1.520 & 1 & 1.459 & Increase \\
\hline 14 & DMU14 & 0 & 0 & 0 & 0 & 0 & 0 \\
\hline 15 & DMU15 & 0.809 & 0.993 & 0.996 & 1.234 & 1.229 & Increase \\
\hline 16 & DMU16 & 0.39 & 1 & 0.971 & 1.038 & 1.007 & Increase \\
\hline 17 & DMU17 & 0.715 & 0.784 & 0.98 & 1.098 & 1.077 & Increase \\
\hline 18 & DMU18 & 0.705 & 0.794 & 0.96 & 1.097 & 1.076 & Increase \\
\hline 19 & DMU19 & 0.382 & 0.417 & 0.97 & 1.039 & 1.007 & Increase \\
\hline 20 & DMU20 & 1 & 1 & 0.074 & 1 & 0.974 & Decrease \\
\hline 21 & DMU21 & 0.709 & 0.79 & 0.98 & 1.098 & 1.076 & Increase \\
\hline 22 & DMU22 & 1 & 1 & 0.939 & 1 & 0.939 & Decrease \\
\hline 23 & DMU23 & 0.725 & 0.73 & 0.975 & 1.044 & 1.018 & Increase \\
\hline 24 & DMU24 & 0.704 & 0.795 & 0.96 & 1.097 & 1.076 & Increase \\
\hline 25 & DMU25 & 0.725 & 1 & 0.975 & 1.044 & 1.018 & Increase \\
\hline 26 & DMU26 & 0.959 & 0.901 & 0.907 & 0.905 & 0.922 & Decrease \\
\hline 27 & DMU27 & 0.49 & 1.03 & 0.971 & 1.038 & 1.007 & Increase \\
\hline 28 & DMU28 & 1 & 0.875 & 0.947 & 0.875 & 0.829 & Decrease \\
\hline 29 & DMU29 & 0.715 & 0.83 & 0.97 & 1.049 & 1.018 & Increase \\
\hline 30 & DMU30 & 0.665 & 0.782 & 1.201 & 1.177 & 1.413 & Increase \\
\hline
\end{tabular}


Question 2: Does teaching realistic mathematics help students use mathematical textbook problems and model simple life situations?

Inputs are Class B who receives realistic mathematics instruction and the output is enhanced mathematical literacy according to Table 4 . The mean percent of performance in the initial test before realistic mathematics test was $20 \%$ and at the end of the training period was $33.3 \%$ and the mean productivity with the Malmquist Index was 53.3\% at a glance, according to Table 4, it can be said that students' mathematical performance after performing realistic mathematics had better results for class B.

Table 4. RME Efficiency

\begin{tabular}{|c|c|c|c|c|c|c|c|}
\hline CLASS B & & & & & & & \\
\hline ROW & DMU & E(MA) & E(AP) & TCI & SECI & FGLR & FPCI \\
\hline 1 & DMU1 & 0.875 & 1 & 0.947 & 0.875 & 0.828 & Decrease \\
\hline 2 & DMU2 & 0.875 & 1 & 0.947 & 0.875 & 0.829 & Decrease \\
\hline 3 & DMU3 & 0.797 & 0.969 & 1.193 & 0.823 & 0.983 & Decrease \\
\hline 4 & DMU4 & 0.719 & 0.81 & 0.984 & 0.888 & 0.874 & Decrease \\
\hline 5 & DMU5 & 1 & 1 & 0.074 & 1 & 0.974 & Decrease \\
\hline 6 & DMU6 & 0.733 & 0.722 & 0.975 & 1.044 & 1.018 & Increase \\
\hline 7 & DMU7 & 0.906 & 0.954 & 0.907 & 0.905 & 0.922 & Decrease \\
\hline 8 & DMU8 & 1 & 1 & 0.939 & 1 & 0.939 & Decrease \\
\hline 9 & DMU9 & 0.784 & 0.715 & 0.98 & 1.098 & 1.076 & Increase \\
\hline 10 & DMU10 & 0.407 & 0.392 & 0.971 & 1.038 & 1.007 & Increase \\
\hline 11 & DMU11 & 1 & 1 & 1.640 & 1 & 1.640 & Increase \\
\hline 12 & DMU12 & 0.87 & 1 & 0.952 & 0.875 & 0.829 & Decrease \\
\hline 13 & DMU13 & 0.704 & 0.734 & 1.520 & 1 & 1.459 & Increase \\
\hline 14 & DMU14 & 0.779 & 0.72 & 0.98 & 1.098 & 1.067 & Increase \\
\hline 15 & DMU15 & 0.993 & 0.809 & 0.996 & 1.234 & 1.227 & Increase \\
\hline 16 & DMU16 & 0.409 & 0.39 & 0.971 & 1.038 & 1.008 & Increase \\
\hline 17 & DMU17 & 0.784 & 0.715 & 0.98 & 1.098 & 1.077 & Increase \\
\hline 18 & DMU18 & 1 & 1 & 0.939 & 1 & 0.939 & Decrease \\
\hline 19 & DMU19 & 0.417 & 0.382 & 0.97 & 1.039 & 1.009 & Increase \\
\hline 20 & DMU20 & 1 & 1 & 0.074 & 1 & 0.974 & Decrease \\
\hline 21 & DMU21 & 0.79 & 0.709 & 0.98 & 1.098 & 1.076 & Increase \\
\hline 22 & DMU22 & 1 & 1 & 0.939 & 1 & 0.939 & Decrease \\
\hline 23 & DMU23 & 0.721 & 0.79 & 0.984 & 0.888 & 0.874 & Decrease \\
\hline 24 & DMU24 & 0.795 & 0.704 & 0.96 & 1.097 & 1.076 & Increase \\
\hline 25 & DMU25 & 0.73 & 0.725 & 0.975 & 1.044 & 1.018 & Increase \\
\hline 26 & DMU26 & 0.901 & 0.959 & 0.907 & 0.905 & 0.923 & Decrease \\
\hline 27 & DMU27 & 0.399 & 0.49 & 0.971 & 1.038 & 1.007 & Increase \\
\hline 28 & DMU28 & 0.875 & 1 & 0.947 & 0.875 & 0.829 & Decrease \\
\hline 29 & DMU29 & 0.83 & 0.715 & 0.97 & 1.049 & 1.018 & Increase \\
\hline 30 & DMU30 & 0.812 & 0.635 & 1.201 & 1.177 & 1.412 & Increase \\
\hline
\end{tabular}


Question 3: Are $\overline{\text { Malmquist and GA }} \overline{\text { MS effective tools }} \overline{\text { in evaluating the performance of } 9^{\text {th }}}$ grade students in mathematics literacy test?

Inputs are Class $\mathrm{C}$ who receives realistic mathematics instruction and problem-solving method and the output is enhanced mathematical literacy according to Table 5. The mean percent of performance in the initial test before realistic mathematics test was $13.3 \%$ and at the end of the training period was $46.6 \%$ and the mean productivity with the Malmquist Index was $80 \%$. At a glance, according to Table 5, it can be said that students' mathematical performance after performing realistic mathematics and problem-solving had better results for Class $\mathrm{C}$.

Table 5. Both Educational Methods Efficiency

\begin{tabular}{|c|l|cccccl|}
\hline CLASS C & & & & & & & \\
\hline ROW & DMU & E(MA) & E(AP) & TCI & SECI & FGLR & FPCI \\
\hline 1 & DMU1 & 0.722 & 0.733 & 0.975 & 1.044 & 1.018 & Increase \\
2 & DMU2 & 1 & 0.875 & 0.947 & 0.875 & 0.829 & Decrease \\
3 & DMU3 & 0.715 & 1.002 & 0.97 & 1.049 & 1.019 & Increase \\
4 & DMU4 & 0.633 & 1 & 1.201 & 1.177 & 1.413 & Increase \\
5 & DMU5 & 0.715 & 1.01 & 0.98 & 1.098 & 1.075 & Increase \\
6 & DMU6 & 0.722 & 1.05 & 0.975 & 1.044 & 1.018 & Increase \\
7 & DMU7 & 0.954 & 0.906 & 0.907 & 0.905 & 0.922 & Decrease \\
8 & DMU8 & 1 & 1.004 & 0.947 & 0.875 & 0.829 & Decrease \\
9 & DMU9 & 0.715 & 0.784 & 0.98 & 1.098 & 1.076 & Increase \\
10 & DMU10 & 0.392 & 0.407 & 0.97 & 1.035 & 1.002 & Increase \\
11 & DMU11 & 0.49 & 0.399 & 0.971 & 1.038 & 1.007 & Increase \\
12 & DMU12 & 0.725 & 1.002 & 0.98 & 1.098 & 1.077 & Increase \\
13 & DMU13 & 0.665 & 0.782 & 1.201 & 1.177 & 1.413 & Increase \\
14 & DMU14 & 0.72 & 0.779 & 0.98 & 1.098 & 1.067 & Increase \\
15 & DMU15 & 0.799 & 1.2 & 0.996 & 1.234 & 1.227 & Increase \\
16 & DMU16 & 0.39 & 1.03 & 0.971 & 1.038 & 1.018 & Increase \\
17 & DMU17 & 0.715 & 0.784 & 0.98 & 1.098 & 1.075 & Increase \\
18 & DMU18 & 0.704 & 1.01 & 0.96 & 1.097 & 1.076 & Increase \\
19 & DMU19 & 1 & 1 & 1.640 & 1 & 1.640 & Increase \\
20 & DMU20 & 0.725 & 0.73 & 0.975 & 1.044 & 1.018 & Increase \\
21 & DMU21 & 0.709 & 1.11 & 0.98 & 1.098 & 1.076 & Increase \\
22 & DMU22 & 1 & 0.999 & 0.939 & 1 & 0.969 & Decrease \\
23 & DMU23 & 0.79 & 0.721 & 0.984 & 0.888 & 0.874 & Decrease \\
24 & DMU24 & 0.704 & 0.795 & 0.96 & 1.097 & 1.076 & Increase \\
25 & DMU25 & 0.725 & 0.73 & 0.975 & 1.044 & 1.018 & Increase \\
26 & DMU26 & 0.959 & 0.901 & 0.907 & 0.905 & 0.913 & Decrease \\
27 & DMU27 & 0.49 & 0.399 & 0.971 & 1.038 & 1.007 & Increase \\
28 & DMU28 & 0.807 & 1.22 & 0.998 & 1.232 & 1.229 & Increase \\
29 & DMU29 & 0.715 & 1.1 & 0.97 & 1.049 & 1.018 & Increase \\
30 & DMU30 & 0.625 & 1.03 & 1.201 & 1.177 & 1.410 & Increase \\
\hline
\end{tabular}

Class D participated in the tests without any training. According to Table 6 , the mean percent of performance in the initial test was $33.3 \%$ and at the end of the first three month of experimental group was $20 \%$ and the total mean productivity with the Malmquist Index was $20 \%$. At a glance, according to Table 6 , it can be said that students' mathematical performance without receiving realistic mathematics methods and problem-solving, had unfavourable results compared to the beginning of the academic year for Class D. 
According to the Tables, the use of the Malmquist Index facilitates the achievement of students in various time periods in the academic year. The Malmquist and the GAMS are used to assess the quality of learning performances of $9^{\text {th }}$ grade.

Table 6. Without Educational Method Efficiency

\begin{tabular}{|c|l|cccccl|}
\hline CLASSD & & & & & & \\
\hline ROW & DMU & E(MA) & E(AP) & TCI & SECI & FGLR & FPCI \\
\hline 1 & DMU1 & 1 & 0.875 & 0.947 & 0.875 & 0.829 & Decrease \\
2 & DMU2 & 0.715 & 0.784 & 0.98 & 1.098 & 1.077 & Increase \\
3 & DMU3 & 1 & 1 & 0.939 & 1 & 0.939 & Decrease \\
4 & DMU4 & 0.382 & 0.417 & 0.97 & 1.039 & 1.009 & Increase \\
5 & DMU5 & 0.969 & 0.797 & 1.193 & 0.823 & 0.982 & Decrease \\
6 & DMU6 & 0.81 & 0.719 & 0.984 & 0.888 & 0.874 & Decrease \\
7 & DMU7 & 1 & 1 & 0.939 & 1 & 0.939 & Decrease \\
8 & DMU8 & 0.79 & 0.721 & 0.984 & 0.888 & 0.874 & Decrease \\
9 & DMU9 & 0.969 & 0.797 & 1.193 & 0.823 & 0.983 & Decrease \\
10 & DMU10 & 0.725 & 0.73 & 0.975 & 1.044 & 1.018 & Increase \\
11 & DMU11 & 0.959 & 0.901 & 0.907 & 0.905 & 0.923 & Decrease \\
12 & DMU12 & 0.49 & 0.399 & 0.971 & 1.038 & 1.007 & Increase \\
13 & DMU13 & 1 & 0.875 & 0.947 & 0.875 & 0.829 & Decrease \\
14 & DMU14 & 0.969 & 0.797 & 1.193 & 0.823 & 0.982 & Decrease \\
15 & DMU15 & 0.81 & 0.719 & 0.984 & 0.888 & 0.874 & Decrease \\
16 & DMU16 & 0.797 & 0.969 & 1.193 & 0.823 & 0.983 & Decrease \\
17 & DMU17 & 0.719 & 0.81 & 0.984 & 0.888 & 0.874 & Decrease \\
18 & DMU18 & 0.969 & 0.797 & 1.193 & 0.823 & 0.983 & Decrease \\
19 & DMU19 & 0.81 & 0.719 & 0.984 & 0.888 & 0.874 & Decrease \\
20 & DMU20 & 1 & 1 & 0.074 & 1 & 0.974 & Decrease \\
21 & DMU21 & 0.959 & 0.901 & 0.907 & 0.905 & 0.922 & Decrease \\
22 & DMU22 & 0.954 & 0.906 & 0.907 & 0.905 & 0.922 & Decrease \\
23 & DMU23 & 1 & 1 & 0.939 & 1 & 0.939 & Decrease \\
24 & DMU24 & 0.715 & 0.784 & 0.98 & 1.098 & 1.076 & Increase \\
25 & DMU25 & 1 & 0.999 & 0.939 & 1 & 0.969 & Decrease \\
26 & DMU26 & 1 & 1 & 1.640 & 1 & 1.640 & Increase \\
27 & DMU27 & 1 & 0.87 & 0.952 & 0.875 & 0.829 & Decrease \\
28 & DMU28 & 0.959 & 0.901 & 0.907 & 0.905 & 0.913 & Decrease \\
29 & DMU29 & 0.81 & 0.719 & 0.984 & 0.888 & 0.874 & Decrease \\
30 & DMU30 & 1 & 1 & 0.074 & 1 & 0.974 & Decrease \\
\hline
\end{tabular}

Question 4: Is it possible to evaluate and compare students' performance using the Malmquist Index and Data Envelopment Analysis?

In this study, data envelopment analysis method and the Malmquist Index were used instead of using statistical methods, t-student test, etc., which reduced the computational volume and the execution of the model using Gams software, facilitated data analysis The final results, according to Table 7 in this study show the feasibility of using data envelopment analysis to compare the performance of students and classes and the Malmquist productivity evaluation Index to determine productivity growth and performance improvement over specified time periods, It can be used as a useful management tool for schools. All tangible and intangible factors are included and consider all factors, especially those that are intangible, according to 
their usability. For example, if only performance calculations were considered for students (tangible factors), in Class A, EMA $=23.3 \%$ and EAP $=36.6 \%$ were considered, as intangible factors were also considered. Class A productivity evaluation with the Malmquist Index was $63.3 \%$, which can be attributed to increased student math literacy and Class A math progress.

Table 7. Class Evaluation Ranking

\begin{tabular}{lccccc}
\hline CLASS & Averag E(MA) & Averag E(AP) & Average(FGLR) & Rank(AP) & PIS \\
\hline class A & $23.30 \%$ & $36.60 \%$ & $63.30 \%$ & 2 & $\uparrow$ \\
\hline class B & $20 \%$ & $33.30 \%$ & $53.30 \%$ & 3 & $\uparrow$ \\
\hline class C & $13.30 \%$ & $46.60 \%$ & $80 \%$ & 1 & $\uparrow$ \\
\hline class D & $33.30 \%$ & $20 \%$ & $20 \%$ & 4 & $\downarrow$ \\
\hline
\end{tabular}

\section{DISCUSSION and CONCLUSION}

\subsection{Conclusion}

This paper deals with the integrated approach of data envelopment analysis method and the Malmquist Productivity Index to evaluate the performance of $9^{\text {th }}$ grade high school students in different time intervals to enhance mathematical literacy. In this paper, the students' relative performance has been evaluated using data envelopment analysis and the Malmquist Index, and the rate of productivity and performance improvement has been determined in two different time intervals. According to the results, mathematics education can be successful when students have the ability to solve everyday real-world challenges based on mathematical facts, methods and concepts (Sumirattana et al., 2017). In solving a problem, the process of applying involves using mathematical knowledge directly. It is a process done in the mathematical world. Therefore, students who have done well in the world of mathematics do not have good results in the real world. Accordingly, students should be familiar with and skilled in mathematical processes such as problem-solving and applying problem-solving strategies and modelling (The national curriculum in, 2014).

On the other hand, a process happening in the math world can improve students' math performance in making connections in the real world. Therefore, it can be concluded that the combination of the two methods of problem-solving and realistic mathematics is effective in promoting mathematical literacy, given that mathematical skills and knowledge defined within the content of the mathematical curriculum are not intended in the use of the word "literacy". Its objective is to evaluate that part of mathematical knowledge that is used in many fields diversely, thoughtfully and insightfully. Mathematical literacy is not limited to mathematical technology knowledge, facts and mathematical calculations (Del Río, Sanz, \& Búcari, 2019) . In fact, we mean a wide, continuous and multi-dimensional spectrum from concepts to very high degrees. One of the most important competencies that are implicitly understood by the concept of mathematical literacy is the ability to design, formulate and solve internal and external mathematical problems in different domains (Alvarez, 2018). Some of the productivity indices in this research are easy understanding, access to information, easy calculation, and access to information to calculate such simple indicators and, if used in conjunction with the total productivity Index, are good tools for identifying weaknesses in the desired field.

The Malmquist Index and the GAMS can be used as a proper model to assess and rank the students in education system by resolving the deficiencies and limitations and by better identification of inputs and outputs since it is able to have a relatively fair evaluation of one way analyzes by examining the inputs and outputs simultaneously. 


\subsection{Discussion}

One of the limitations of the Malmquist productivity indices is that they are very misleading if used alone and can be relatively difficult to obtain data needed for comparative purposes, so it is better to calculate them along with other models of data envelopment analysis. Despite the benefits of this Index to its limitations, it is recommended to use it when there are multiple inputs and outputs.

Because this Index provides a quantitative way to link everything from quality to process timing and dozens of other important performance indicators to profitability, it can be effective in the productivity evaluation of industry, agriculture and educational institutions. GAMS Software can be introduced as a good instrument for evaluating students' grades with different mathematical models in several time frames (Kalvelagen, n.d.), (Pintér, 2007).

\section{ORCID}

Niusha Mostoli (D) https://orcid.org/0000-0001-6639-6878
Mohsen Rostamy (D) https://orcid.org/0000-0001-6105-7674

\section{REFERENCES}

Adams, R., \& Wu, M. (2000). Pisa 2000 Technical (OECD Organization for Economic Cooperation and Developmant). Paris: Publications 2 rue André-Pascal, 75775 Cedex 16, France.

Alimohammadlou, M., \& Mohammadi, S. (2016). Evaluating the Productivity Using Malmquist Index Based on Double Frontiers Data. Procedia - Social and Behavioral Sciences, 230(May), 58-66. https://doi.org/10.1016/j.sbspro.2016.09.008.

Alvarez, R. (2018) ."A Focus on Mathematical Literacy to Increase Student Understanding and Performance". (Master's dissertation) . New York, USA. Retrieved May5 , 2019 , from https://digitalcommons.brockport.edu/ehd theses/1169.

Andersen, P., \& Petersen, N. C. (1993). A Procedure for Ranking Efficient Units in Data Envelopment Analysis process (DEA). Management Science, 39(10), 1261-1264. https://doi.org/10.2307/2632964.

Basic, T. H. E., \& Model, C. C. R. (2005). The Basic CCR Model. In Data Envelopment Analysis (pp. 21-39). Boston: Kluwer Academic Publishers. https://doi.org/10.1007/0306-47541-3_2.

Breen, S., Cleary, J., \& Shea, A. O. (2009). An investigation of the Mathematical literacy of first year third-level students in the Republic of Ireland. International Journal of Mathematical Education, 40(2), 229-246. https://doi.org/10.1080/00207390802566915.

Burnett, N. (2005). literacy for life. Education for All . France: Printed by Graphoprint, Paris ISBN 92-3-104008-1@UNESCO .https://unesdoc.unesco.org/ark:/48223/pf0000141639.

Chen, C., \& Lin, M. (2006). Using DEA to Evaluate R \& D Performance in the Integrated Semiconductor Firms - Case Study of Taiwan, International Journal of The Computer the Internet and Management, 14(3), 50-59.

Del Río, L. S., Sanz, C. V., \& Búcari, N. D. (2019). Incidence of a hypermedia output material on the teaching and learning of mathematics. Journal of New Approaches in Educational Research, 8(1), 50-57. https://doi.org/10.7821/naer.2019.1.334.

Diewert, W. E., \& Fox, K. J. (2010). Malmquist and Törnqvist productivity indexes: Returns to scale and technical progress with imperfect competition. Journal of Economics/ Zeitschrift Fur Nationalokonomie, 101(1), 73-95. https://doi.org/10.1007/s00712-0100137-0.

Douglas, W., Caves ,E., Laurits, R., \& Christensen, W. E. D. (2012). The Economic Theory of Index Numbers and the Measurement of Input, Output, and Productivity Author ( s ): Douglas W. Caves, Laurits R. Christensen, W . Erwin Diewert Reviewed work ( s ): 
Published by : 50(6), 1393-1414.

Esther, M., Pérez, M., Duque, A. P. G., \& García, L. C. F. (2018). Game-Based Learning: Increasing the Logical-Mathematical , Naturalistic, and Linguistic Learning Levels of Primary School Students, 7(1), 31-39. https://doi.org/10.7821/naer.2018.1.248.

Fare, R., Grosskopf, S., Lindgren, B., Roos, P. (1992). A Non-Parametric Malmquist Approach. The Journal of Productivity Analysis, 3(1), 85-101. Retrieved from https://link.springer.com/content/pdf/10.1007\%2FBF00158770.pdf.

Färe, R., Grosskopf, S., \& Roos, P. (1995). Productivity and quality changes in Swedish pharmacies. International Journal of Production Economics, 39(1-2), 137-144. https://doi.org/10.1016/0925-5273(94)00063-G.

Freudenthal, H. (1973). Mathematics as an educational task, Reidel. Van den Heuvel-Panhuizen, M. (2000). Mathematics education in theNetherlands: A guided tour. Freudenthal Journal, Utrecht University.

Gatabi, A. R., Stacey, K., \& Gooya, Z. (2012). Investigating grade nine textbook problems for characteristics related to mathematical. literacy Math Ed Res Journal, (2012) 24, 403421. https://doi.org/10.1007/s13394-012-0052-5.

Gravemeijer, K. P. E. (1994). Developing realistic mathematics education. Journal of Curriculum Studies ,(1994) 11, 24-34. https://research.tue.nl/en/publications/developingrealistic-mathematics-education.

Gravemeijer, K., Terwel, J.(2000). Hans Freudenthal: a mathematician on didactics and curriculum theory. Journal of Curriculum Studies2000, VOL. 32, NO. 6, 777 \pm 796.

Hosseinzadeh Lotfi, F., Jahanshahloo, G. R., Khodabakhshi, M., Rostamy-Malkhlifeh, M., Moghaddas, Z., \& Vaez-Ghasemi, M. (2013). A Review of Ranking Models in Data Envelopment Analysis. Journal of Applied Mathematics, 2013 NO. (14), 1-20. https://doi.org/10.1155/2013/492421.

Kalvelagen, E. (2002). Data and Software Interoperability with Gams:A UserPerspectiveModelingLanguages, Solving Multi-Objective Models with GAMS Journal, http://citeseerx.ist.psu.edu/ doi=10.1.1.201.332\&rep=rep1\&type=pdf

Koçak, D., Türe, H., Atan, M. (2019). Efficiency Measurement with Network DEA : An Application to Sustainable Development Goals. International Journal of Assessment Tools in Educatio, 6(3), 415-435.

Koyuncu, İ., Guzeller, C. O., \& Akyuz, D. (2016). The development of a self-efficacy scale for mathematical modeling competencies. International Journal of Assessment Tools in Education, 4(1), 19-35. https://doi.org/10.21449/ijate.256552

Lange, J. De. (1987). Mathematics, Insight and Meaning: Teaching, Learning and Testing of Mathematics for the Life and Social Sciences. Freudenthal Institute. Retrieved from https://books.google.com/books?id=wee5pwAACAAJ.

Maudos, J., \& Pastor, J. M. (1998). Human capital in OECD countries: Technical change , efficincy and Joaquín Maudos , José Manuel Pastor and Lorenzo Serrano.

OECD. (2002). Reading for Change: Performance and Engagement across Countries. OECD. https://doi.org/10.1787/9789264099289-en.

Pintér, J. D. (2007). Nonlinear optimization with GAMS /LGO. Journal of Global Optimization, 38(1), 79-101. https://doi.org/10.1007/s10898-006-9084-2.

Polya, G. (1962). Mathematical discovery: On understanding, learning and teaching problem solving. New York: Wiley, (vol. 1).

Programme for International Student Assessment., \& Organisation for Economic Co-operation and Development. (2009). Learning mathematics for life: a perspective from PISA. OECD.

Rosenthal, R. E. (2007). A GAMS Tutorial. GAMS - A User's Guide, 5-26.

Sari, Y. M., \& Valentino, E. (2016). An Analysis of Students Error In Solving PISA 2012 And 
Its Scaffolding, 1(2), 90-98.

Sinuany-Stern, Z., Mehrez, A., \& Barboy, A. (1994). Academic departments efficiency via DEA. Computers \& Operations Research, 21(5), 543-556. https://doi.org/10.1016/03050548(94)90103-1.

Stacey, K., Almuna, F., Caraballo, R. M., Lupia, L., Park, K. M., Perl, H., \& Rafiepour, A. (2015). PISA' s Influence on Thought and Action in Mathematics Education. https://doi.org/10.1007/978-3-319-10121-7.

Sumirattana, S., Makanong, A., \& Thipkong, S. (2017). Using realistic mathematics education and the DAPIC problem-solving process to enhance secondary school students' mathematical literacy. Kasetsart Journal of Social Sciences, 38(3), 307-315. https://doi.org/10.1016/j.kjss.2016.06.001.

The national curriculum in. (2014, December), https://www.gov.uk/dfe/nationalcurriculum .

Thomson, S., Hillman, K., \& Bortoli, L. De. (2013). A Teacher's Guide to PISA Mathematical Literacy. OECD Programme for International Student Assessment (PISA Australia). Retrieved from https://research.acer.edu.au/ozpisa/12.

Tohidi, G., \& Razavyan, S. (2013). A circular global profit Malmquist productivity index in data envelopment analysis. Applied Mathematical Modelling, 37(1-2), 216-227. https://doi.org/10.1016/j.apm.2012.02.026.

Wang, Y. M., \& Lan, Y. X. (2011). Measuring Malmquist productivity index: A new approach based on double frontiers data envelopment analysis. Mathematical and ComputerModelling, 54(11-12), 2760-2771. https://doi.org/10.1016/j.mcm.2011.06.064

Wei, Z., \& Hao, R. (2011). The Role of Human Capital in China's Total Factor Productivity Growth. The Developing Economies, 49(1), 1-35. 


\section{APPENDIX}

\section{Score INPUT \& OUTPUT Any Qestion}

An example of the problem based on realistic mathematics education and PISA problemsolving (2015):

A pizza seller sells two types of pizza with the same thickness in a small size with a diameter of $30 \mathrm{~cm}$, and a price of $30 \$$, in a large size with a diameter of $40 \mathrm{~cm}$, at a price of $40 \$$, Which pizza is worth buying?

\section{DAPIC Math Problem-solving}

1. Define: definition of the problem with the student experiences, What do I want to do (Pizza shape, definition of the circle) 0.25

2. Assess: Separation of keywords in the problem, assuming data as hypotheses. (Definition of the area and perimeter of the circle, smaller and larger) 0.25

3. Plan: Guessing the operation, designing and determining the program. (Which approach is appropriate) 0.25

4. Implement: implementation of plans and guesses, make changes as needed. (Find the perimeter and area and the appropriate ratio) 0.25

5. Communicate: assessing and analyzing the result, reviewing the problem back. (Review and analysis of the solution) 0.25

\section{Realistic Mathematics Education (RME)}

1. Guided reinvention: a hypothesis to create knowledge and innovation (innovation and communication with the real world) 0.25

2. Didactical phenomenology: Creating a comprehensive description of an experienced daily and real life phenomenon (the real experience of buying pizza) 0.25

3. Self-developed model: The model is developed by the student himself from an informal to formal math. (Communication of Reality with Math) 0.25 


\section{GAMS Software with the Malmquist Index}

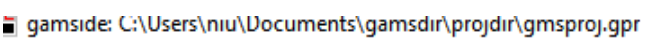

ile Edit Search Windows Utilities Model Libraries Help

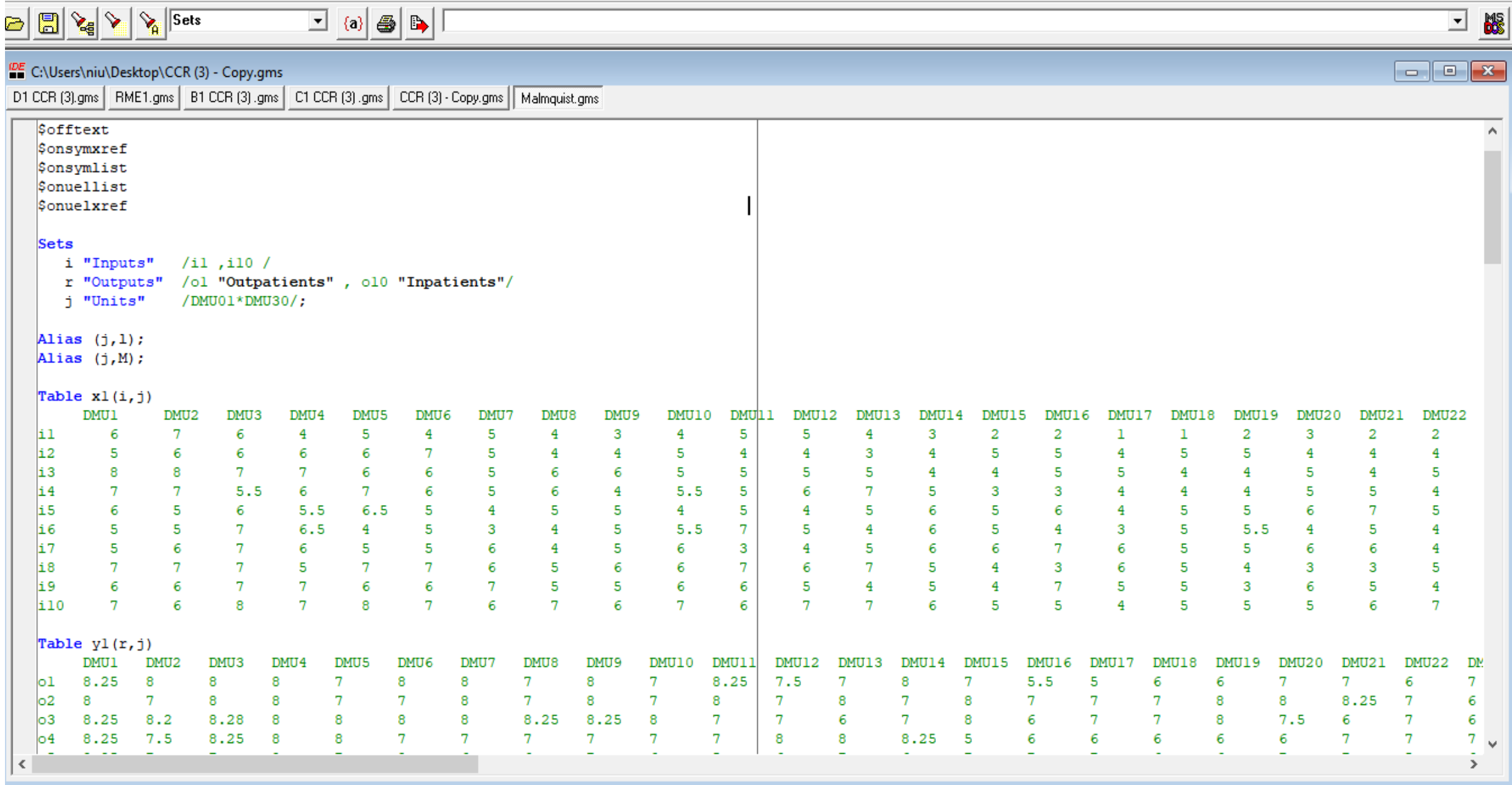


IFE gamside: C:IUsers\niu\Documents\gamsdirlprojdirlgmsproj.gpr

File Edit Search Windows Utilities Model Libraries Help

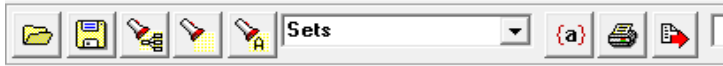

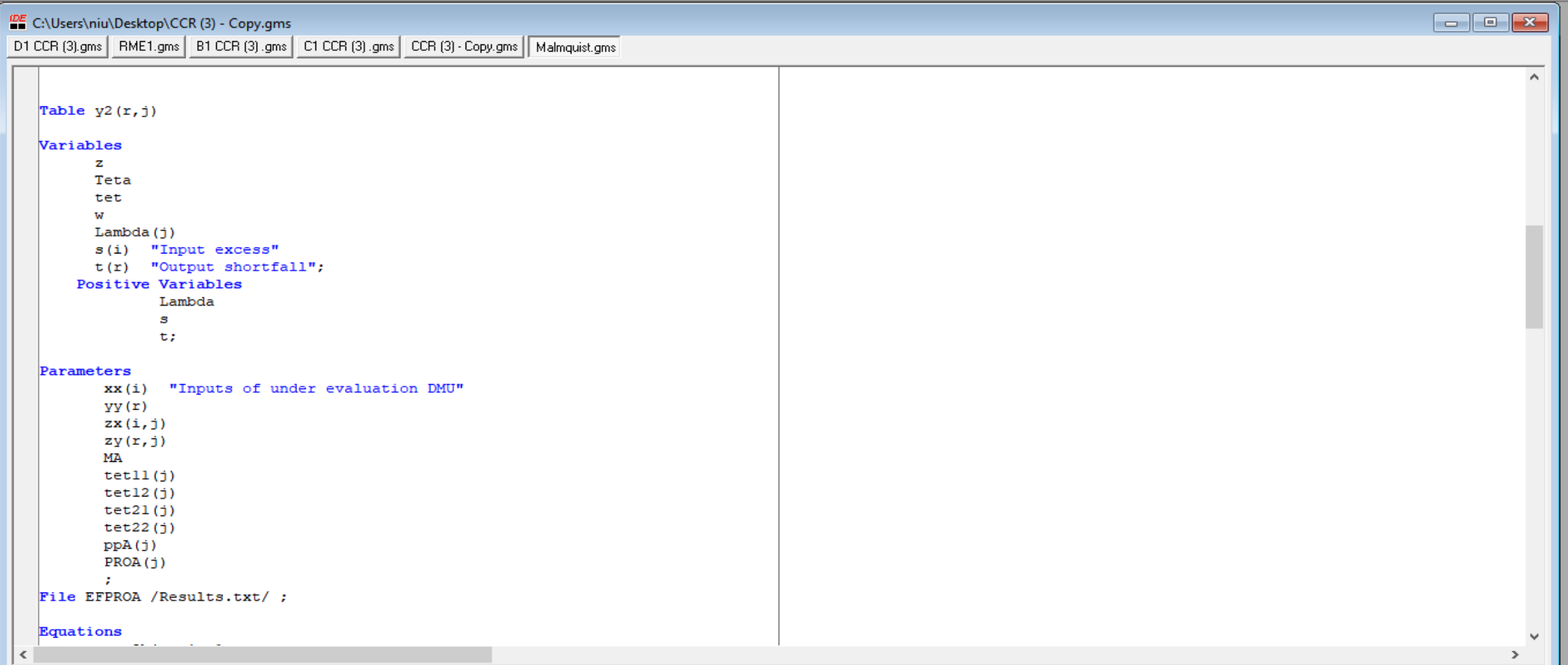


File Edit Search Windows Utilities Model Libraries Help

IDE C:IUsers Iniu \Desktop\CCR (3) - Copy.gms

\begin{tabular}{|l|l|l|l|l|l}
\hline D1 CCR (3).gms & RME1.gms & B1 CCR (3).gms & C1 CCR (3).gms & CCR (3) - Copy.gms & Malmquist.gms
\end{tabular}

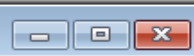

$$
\begin{array}{|l|l}
\hline \operatorname{PpA}(j) \\
\text { PROA }(j)
\end{array}
$$

File EFPROA /Results.txt/ ;

Equations

Objective1

Constl(i)

Const2 ( $r$ )

Const3 3

Const 4 (i)

objectivel.. teta=e=tet:

Const $1(i) \ldots \quad$ Sum $(j, z \times(i, j) * \operatorname{Lambda}(j))=1=\operatorname{Tet} x^{*} \mathrm{xx}(i)$

Const $2(r) \ldots \quad$ Sum $(j, z y(r, j) * \operatorname{Lambda}(j))=g=y y(r)$;

Const3.. Sum $(j$, Lambda $(j))=e=1$

Models BCC_Phase1 /Objective1, Const1, Const2, Const3/

loop (j,

loop $(I, x 1(i, j)=x 1(i, j)+0.010)$;

loop $(I, x 2(i, j)=x 2(i, j)+0.010)$

$1 ;$

loop $(j$, loop $(r, z y(r, j)=y 1(r, j)))$; 